Gadjah Mada International Journal of Business

May-August 2009, Vol. 11, No. 2, pp. 253-273

\title{
MANAGERIAL VIEWS OF SUPPLY CHAIN COLLABORATION An Empirical Study
}

\author{
Ramaswami Sridharan
}

University of Newcastle in Australia

\section{Togar M. Simatupang}

School of Business and Management, Bandung Institute of Technology, Bandung, Indonesia

This paper is carried out to empirically examine managerial perceptions on the relationship between supply chain collaboration practice and operational performance. The framework suggests that collaborative practice is characterised by three distinct factors: (1) decision synchronisation, (2) information sharing, and (3) incentive alignment, which enable the chain members to effectively match supply with customer demand. An important question is whether or not collaborative practice leads to better operational performance. A survey research was employed to assess the relationship between collaborative practice and operational performance of New Zealand companies. The survey results show significant positive impacts of key factors of collaborative practice on operational performance. The findings suggest that information sharing, decision synchronisation, and incentive alignment are important determinants of operational performance. This study demonstrates that the chain members need to understand the role of different key factors of collaborative practice that can be redesigned to leverage operational performance.

Keywords: channel relationships; collaboration; incentive alignment; information sharing; New Zealand; supply chain management; survey research 
Gadjah Mada International Journal of Business, May-August 2009, Vol. 11, No. 2

\section{Introduction}

Global competition has fundamentally changed the economic environment of firms along the supply chain. End customers have greater control over the buying process and the financial ability to make choices of product features. It is not surprising that the global market results in higher demand uncertainty with shorter product life cycles and greater variety (Fisher 1997). As interdependence increases between firms, they need to collaborate to effectively manage flows of products along the entire value-added supply chain to be available for end customers (Whipple and Russell 2007). Collaboration enables both parties to combine knowledge and capability better than acting in isolation (Dyer and Singh 1998). Retailers, for instance, know consumer preferences due to their direct access to end customers, but are lacking in knowledge of product design and delivery. Partnering suppliers, on the other hand, have better knowledge of product design, production capability, and delivery capability.

Supply chain collaboration brings advantages to participating members, and enables them to experience increases in their common market shares and profitability (Parks 1999). These advantages can be realised only if both parties work together to speed up the decision-making process in delivering the right product to the right place at the right time in the right condition for the right cost (Fisher 1997). As an illustration, the cooperation between K-Mart and Lee Apparel shows that both parties reap the advantages of collaboration to match supply and demand. K-Mart shares points-of-sale (POS) data with Lee. Lee uses this data to monitor the exact products sold, including color, size, and style, in each K-Mart store. With this information in hand, Lee knows which products need to be restocked at each K-Mart location, and is thus able to coordinate its production and distribution plans to accommodate its major customers' needs. Lee can also identify early warning signs of merchandising problems for Lee's products at particular KMart locations. Early warning signs help both parties to devise quick responses that lead to reductions in stock outs and markdowns, thereby improving customer service and sales.

Supply chain collaboration has become a central issue in supply chain management as it facilitates close cooperations amongst chain members (Spekman et al. 1998). Although the basic tenet of supply chain management is the integration of key business processes along the supply chain that create value for end customers and other stakeholders, the main key is managing the interface process of decision making amongst interdependent firms that voluntarily work together as a supply chain (Stank et al. 2001; Zhao et al. 2001). Previous researchers have addressed the issue of supply chain collaboration as the central part of supply chain management. Bowersox et al. (2000) emphasize that the con- 
cept of integrated supply chain management is a collaborative-based strategy to link cross-enterprise business operations to achieve a shared vision of market opportunity. In a similar vein, Ballou et al. (2000) argue that supply chain management includes interfirm cooperation that coordinates product movements across the legal boundaries of independent firms. Stank et al. (2001) also emphasize the fact that supply chain management involves some levels of coordination of activities and processes both intra- and interfirm.

Given the significance of supply chain collaboration, this research contributes to the literature of supply chain collaboration through characterizing collaborative practice into three interrelated enabling factors: (1) decision synchronization, (2) information sharing, and (3) incentive alignment. The research also tests hypotheses on whether or not the three factors of collaborative practice positively contribute to operational performance. Survey research was carried out to assess the relationship between collaborative practice and performance.

The study is organized as follows. First, related research as the foundation for this paper is presented. The next section proposes an operating definition for collaborative practice that consists of three enabling factors, namely decision synchronization, information sharing, and incentive alignment. Research hypotheses are also developed in this section to describe the influence of collaborative practice on operational performance. Afterwards, the research method, comprising data collection, development of measures, and analysis is given. Findings and discussion are subsequently presented. Finally, the paper provides concluding remarks and recommendations for further research.

\section{Related Research}

A review of related research reveals an increased interest in supply chain collaboration. The literature can be classified into the development of the concept of supply chain collaboration and empirical research. The conceptual study on supply chain collaboration deals with the definitions and components or success factors of supply chain collaboration. The empirical research provides evidence obtained from the survey and case studies that describe the extent to which firms have adopted the concept of collaboration and discussions of factors that facilitate or hamper the implementation of supply chain collaboration. This section presents the previous work that relates to the conceptualization, success factors, and empirical evidence of supply chain collaboration.

The literature provides diverse definitions of the concept of supply chain collaboration. The term "supply chain collaboration" has been used to describe partnership, logistics alliance, and coordination. Johnston and Lawrence (1988) define partnership in the supply chain as independent firms that work closely together to manage 
Gadjah Mada International Journal of Business, May-August 2009, Vol. 11, No. 2

the flow of goods and services along the entire value-added chain. Similarly, Buzzell and Ortmeyer (1995) propose partnership as the cooperation between suppliers and retailers in which the parties agree on objectives, policies, and procedures for ordering and physical distribution of suppliers' products to end customers. Narus and Anderson (1996) use partnership to describe the cooperations amongst independent but related firms to share resources and capabilities to meet their customers' most extraordinary needs. Bowersox (1990) uses logistics alliance to characterize the cooperations amongst independent firms along a supply chain that share resources in delivering products to ultimate customers. Although previous researchers have used different terms for collaboration, it is important to note that collaboration is an evolving process rather than a static process that lies between adversarial relationships and joint ventures (Lambert et al. 1999). Therefore, a useful definition of supply chain collaboration is the process of independent firms working together to deliver products and services to end customers for the basic purpose of optimizing higher long-range profit for all chain members than can be achieved by acting alone (Simatupang and Sridharan 2002).

Besides definitions, the success factors of supply chain collaboration also vary amongst previous researchers. Buzzell and Ortmeyer (1995) propose key elements of improvement opportunities from collaboration, namely better assortment planning, faster new product development, more effective replenishment, faster order processing, better inventory control, more effective receipt and distribution, and better store selling tasks. According to Spekman et al. (1998), supply chain collaboration occurs when participating members share information freely, work together to solve common problems, devise joint planning, and make their success interdependent. Ballou et al. (2000) emphasize three components of inter-organizational coordination: (1) performance metrics, (2) information sharing, and (3) benefits allocation. Lee (2000) proposes the concept of supply chain integration that incorporates information sharing, logistics coordination, and organizational relationship linkages. Mentzer et al. (2000) argue that supply chain collaboration is characterized by the sharing of information, knowledge, risk, and profit. In addition, Simatupang and Sridharan (2005) assert that information sharing, decision synchronization, incentive alignment, collaborative performance systems, and process improvements are instruments used to enable supply chain collaboration.

The bulk of empirical research shows that more and more firms are attracted to implementing supply chain collaboration (Bowersox 1990; Whipple et al. 2007), and concludes that collaboration brings positive benefits to participating members (Buzzell and Ortmeyer 1995; Stank et al. 2001; Zhao et al. 2001). According to Mohr 


\section{Sridharan \& Simatupang-Managerial Views of Supply Chain Collaboration}

and Spekman (1994), the success of collaboration depends on commitment and trust, effective communications to specify roles, responsibilities, and expectations, and the conflict resolution techniques of joint problem solving. Stank et al. (2001) find that internal collaboration mediates the relationship between external collaboration and logistical service performance. Spekman et al. (1998) discover that information sharing is a key ingredient to reducing costs and improving customer satisfaction. Stank et al. (1999) also find the positive effect of the collaborative practice with key customers on logistics cost and customer service. Furthermore, Sheu et al.(2006) recently find from a case study that supply chain architecture in information sharing, inventory systems, coordination, and IT capabilities affects the level of collaboration.

Another stream of empirical research relies on the use of a collaborative management process to facilitate supply chain collaboration (Ireland and Bruce 2000). Kurt Salmon Associates promotes efficient-consumer-response (ECR) that facilitates planning and execution for efficient promotion, replenishment, store assortment, and product introduction (Barratt and Oliveira 2001; Frankel et al. 2002). Another initiative called vendor-managed inventory (VMI) delegates stocking decisions to main suppliers in such a way the suppliers are responsible for monitoring stock levels and replenishing products sold at the retailer stores (Lee et al. 1997; Whipple et al. 2007).
Sherman (1998) reports a recent movement in Collaborative Planning, Forecasting, and Replenishment (CPFR). CPFR is proposed to enable participating members across the supply chain to remain competitive by taking a holistic approach to delivering products to ultimate customers. This approach has the potential to deliver increased sales, interorganizational streamlining and alignment, administrative and operational efficiency, improved cash flows, and improved return on assets.

\section{Conceptual Model}

As the nature of collaboration is to optimise profitability, the chain members need to plan, execute, and control key decisions at the interface boundaries related to defining and delivering products to ultimate customers that lead to mutual advantage. The collaborative supply chain assumes that the chain members synchronize decision making across a supply chain, share information to make effective decisions that improve performance, and employ incentive schemes for specifying reward and punishment mechanisms (Lee et al. 1997; Simatupang and Sridharan 2002). As a consequence, the structure of ongoing collaboration can be characterized by three enabling factors of collaborative practice: (1) information sharing, (2) decision synchronization, and (3) incentive alignment (Simatupang and Sridharan 2005).

The three factors of collaborative practice are expected to facilitate the 
Gadjah Mada International Journal of Business, May-August 2009, Vol. 11, No. 2

chain members into cross-organizational cooperation in realizing collaborative benefits. To operationalize this concept, a hypothetical framework is developed to link the three factors of collaborative practice to operational performance. The framework consists of two variables: (1) collaborative practice and (2) consequences of collaborative practice. Briefly, it suggests that collaborative practice positively affects operational performance. Hypotheses are developed based on this conceptualization and previous work in supply chain collaboration. The remaining part of this section presents these hypotheses.

Information sharing can be defined as a process that facilitates the chain members to capture and disseminate timely, relevant, and accurate information such that the recipient is able to plan, execute, and control supply chain operations. Effective information sharing provides a shared basis for concerted actions by different functions across interdependent firms (Whipple et al. 2002). Examples of shared information include pointsof-sale (POS) data, updated forecasts, production and delivery schedules, inventory levels, delivery lead-times, and inventory carrying costs. Information sharing also facilitates clarity about demand, the fulfillments process, and common performance for all participating members (Zhao et al. 2001). Collaborative initiatives, such as Efficient Consumer Response (ECR), Quick Response (QR), and VendorManaged Inventory (VMI), are based on the concept of information sharing amongst the chain members to match supply and demand(Simchi-Levi etal. 2007; Sherman 1998). Fisher (1997) finds that information sharing can yield significant performance improvements in all chain members, such as cohesive market focus, better coordination of sales and demand fulfillment, and minimum risks associated with demand uncertainty. Information sharing provides a unifying visibility for the efforts of chain members to improve operational performance, thereby enabling the chain members to forecast accurately, reduce order variability, shorten delivery lead time, and reduce inventory levels (Fisher 1997; Lee et al. 1997). Companies like Ford and its vendors, Dell and its suppliers, WalMart and Procter and Gamble (P\&G) are widely known to practice information sharing to reduce working capital and inventories (Simchi-Levi et al. 2007). Therefore, there is a direct link between the availability and the quality of timely information and the performance of a supply chain. Relevant to this conceptualization as well as on the basis of this discussion, the following hypothesis is proposed.

Hypothesis 1. Information sharing is positively related to operational performance.

Decision synchronization refers to a joint initiative of collaborative decision making within planning and operational contexts for identifying key decision points, distributing responsibilities, reconciling conflicting goals, sharing resources, handling exceptions, 


\section{Sridharan \& Simatupang-Managerial Views of Supply Chain Collaboration}

and solving problems (Bowersox et al. 2003; Mohr and Spekman 1994). The planning context integrates decisions on long-term planning and measures, such as selecting target markets, product assortments, customer service level, delivery schedule, promotion, and forecasting. The operational context integrates order generation and delivery process that can ship schedules and replenish products to the stores. Decision synchronization encourages the chain members to have a sense of belonging in which all decisions work toward a common goal of serving end customers (Lee et al. 1997; Morash and Clinton 1998). This reduces the gap between delivery requirements and actual delivery, thereby improving customers' perceptions of fulfillment performance (Ramdas and Spekman 2000). Customers are satisfied as they find products suited to their preferences and tastes at the right time and right price. Many improvements are made possible by employing decision synchronization and the associated dynamic control amongst autonomous members of the supply chain to align different decision sharing options with varying flexibility requirements (Lee et al. 1997). Decision synchronization facilitates the chain members to reassign decision rights in order to be able to identify exceptions and make effective decisions like stocking, distribution, outsourcing, and shipping, thereby providing responsibilities for improving the performance of the supply chain (Holweg et al. 2005; Simatupang and Sridharan 2005). Bowersox et al.
(2000) report that decision synchronization contributes to a reputation of on-time delivery and consistent product availability. This discussion suggests the following hypothesis.

Hypothesis 2. Decision synchronization is positively related to operational performance.

Incentive alignment refers to the degree to which chain members share costs, risks, and benefits (Narayanan and Raman 2004; Simatupang and Sridharan 2005). The costs, such as administration and technology investment, need to be shared fairly amongst the chain members in order to maintain the commitment of each party to the collaborative efforts (Narus and Anderson 1996). Moreover, chain members commit to the collaborative efforts if they can realize and capture relevant benefits that contribute to their future survival. Benefits of collaboration include both commercial gains, such as increased sales, and performance improvements, such as lowered inventory costs (Corbett et al. 1999). Incentive alignment also involves risk sharing among the chain members in managing demand, supply, and price uncertainties. Setting and applying appropriate incentives, such as revenue sharing, transfer pricing, consignment, shortage reimbursement, and backlog penalty, motivate the chain members to take decisions compatible with the achievement of higher performance (Giunipero et al. 2001; Lee and Whang 1999). The chain members are encouraged to ensure on- 
time delivery and responsiveness in the presence of incentive alignment tied to customer service at a just-intime level (Narayanan and Raman 2004). It can be stated that incentive alignment facilitates the chain members to act consistently with improving the performance of the supply chain (Lee and Whang 1999). This observation suggests the following hypothesis.

Hypothesis 3. Incentive alignment is positively related to operational performance.

\section{Research Method}

A survey method is utilized to gain responses from sample that reflects various degrees of collaboration between suppliers and retailers. In this setting, survey research is useful to accommodate diverse respondents and thereby has a high level of generalizability (Pinsonneault and Kraemer 1993). In addition, linking interface coordination and key performance outcomes provides additional insights into current practice of collaboration that affects performance. Empirical findings, which confirm this relationship, extend the validity of collaborative practice.

The development of research instruments follows three steps: (1) literature review, (2) conceptualization, and (3) pre-test. The first phase consists of reviewing literature on supply chain collaboration. The literature indicates that the issue of supply chain collaboration is of substantial interest to many firms, and serves as an active research arena with the advent of information technology. Second, a preliminary conceptual framework is developed to link the collaborative practice and operational performance. There are three interface dimensions based on the interface processes between the chain members: (1) decision synchronization, (2) information sharing, and (3) incentive alignment. A set of questionnaires was developed to capture and represent the concept of supply chain collaboration. Scales for the study comprised newly generated items and items that have been used previously in the literature. To develop a scale, the domain of a variable was itemized into a set of activities (Cavana et al. 2001). Five items were developed to measure each dimension of supply chain collaboration. A panel consisting of practitioners and academics was asked to review and modify initial items. These experts clarified and suggested useful terms and were confident that the items posed in the questionnaires accurately reflected the concept of collaboration.

Finally, a pre-test was carried out to confirm the stability with which the items measure the concept of supply chain collaboration. A panel of practitioners and researchers was asked to identify ambiguous items, poorly worded questions, and poor instructions to answer the questionnaires. Several items were rewritten after evaluation by the panel. The panel also found no major problems with any of the response formats, directions, and 
other survey procedures. Additional evaluation was also made to ensure the consistency of the measures used in prior research. Several items were modified slightly after this evaluation. The final set of questionnaires reflects the changes.

The final set of questionnaires contains general characteristics of respondent, items related to the measurement of the three dimensions of collaboration, and items intertwined with the measurement of performance variables. The measures of scale are described as follows. The information sharing (IS) scale describes the extent to which the chain members share private information required for planning, executing, and controlling supply chain operations. Items of the IS scale include data exchange about promotional events, demand forecasts, inventory holding costs, on-hand inventory levels, and order tracking. These measurement items are adapted from Zhao et al. (2001) and Whipple et al. (2002). A five-point format $(1=$ strongly disagree, 5 = strongly agree) is used for each item.

The decision synchronization (DS) scale describes the extent to which the parties make decisions jointly rather than independently. The chain member's perception on DS is measured using five parallel items. These items capture joint decisions on reducing demand fluctuations, developing joint forecasts, co-managing inventory requirements, ensuring on-time delivery, and improving product availability. The five items are adapted from previous researchers (Morash and Clinton 1998; Ramdas and Spekman 2000). Each item is assessed on a fivepoint format ranging from 1 (strongly disagree) to 5 (strongly agree), with a defined neutral point at 3 .

The incentive alignment(IA) scale describes the extent to which the chain members share costs, risks, and benefits to encourage continuous improvement. The IA scale is adapted from Giunipero et al. (2001) and Morash and Clinton (1998), and measured by a five-item scale assessing risks sharing associated with demand uncertainties, shared savings of lowering inventory costs, investment sharing of collaborative efforts, joint effort for increasing sales, and benefit sharing. Each item is assessed with the range from 1 (strongly disagree) to 5 (strongly agree), with a defined neutral point at 3.

The measures of supply chain performance used in this study include fulfillment, inventory, and responsiveness (Ramdas and Spekman 2000). Fulfillment measures the extent to which the collaborative practice affects the ability of the chain members to satisfy consumer delivery dates (Croxton 2003; Morash and Clinton 1998; Ramdas and Spekman 2000). This includes on-time delivery (i.e., the percentage of all orders sent on or before the promised delivery date), accuracy (i.e., the percentage of correct orders), and fill rate (i.e., amount of order filled as compared to amount requested). Inventory refers to the extent to which the collaborative prac- 
Gadjah Mada International Journal of Business, May-August 2009, Vol. 11, No. 2

tice affects inventory and its associated costs. This includes merchandise inventory turnaround, a decrease in inventory days-of-supply, and a decrease in inventory carrying cost (Ramdas and Spekman 2000). Responsiveness measures the extent to which the collaborative practice affects leadtime and flexibility to accommodate demand changes, and this measure is adapted from Wisner (2003). A fivepoint format ranging from 1 (strongly disagree) to 5 (strongly agree) is used for each item.

The unit of analysis in this research is a specific retailer-supplier relationship. This unit of analysis is chosen for several reasons. First, the retailer is an agent who ultimately meets the end customer demands of the entire supply chain (Whipple and Russell 2007). The retailer's position is crucial to improving supply chain performance in terms of customer service for end customers. The retailer also has intimate knowledge of demand condition because of direct contact with end customers. Sharing current and advanced demand information with the supplier may mitigate the propagation of demand variation faced by the supplier (Lee et al. 1997). If the retailer shares private information about advanced customer demand with the supplier, the supplier might be able to anticipate this demand by placing a material order in advance or maintaining an inventory buffer to avoid product stockouts. At the same time, the supplier can use points-of-sale (POS) data to create a quick response to the retailer's store shelves at predetermined levels (Parks 1999).

Second, the geographical proximity of New Zealand companies tends to force the domestic manufacturers to ship products to their retailers directly rather than through distributors (Sankaran 2000). This direct link makes the retailer's position significant for the swift flow of the supplier's products to end customers. The sample also represents a specific relation of a distributor and a retailer. Distributor companies in New Zealand mainly accommodate products from overseas manufacturers to be delivered to their retailers.

Third, the retailer-supplier link as the unit of analysis is consistent with previous research on advanced initiatives -such as efficient consumer response(ECR), vendor-managed inventory (VMI), and collaborative planning, forecasting, and replenishment (CPFR)- that employ a similar unit of analysis (Barratt and Oliveira 2001).

\section{Data Collection}

The conceptualization of collaborative relationships as multidimensional in nature requires substantial amount of information regarding supplier-retailer relationships in examining the proposed conceptual model. Supplier firms can be manufacturers that directly deliver their products to retailers or to distributors that mediate manufacturers and retailers. The retailers often sell the majority of a partner supplier's products. Those compa- 


\section{Sridharan \& Simatupang-Managerial Views of Supply Chain Collaboration}

nies operate with consumer products. This sample restriction reduces the extraneous sources of variation that might lower consistency of responses.

Retail industry in New Zealand consists of retailers of various sizes, ranging from small owner operators, general merchandise chains, specialized chains, traditional departments stores, to big multinational retailers such as Foodstuffs, Progressive Enterprises, Arthur Barnett, Briscoes, Farmers, K-Mart, The Warehouse, Baby Factory, Hannahs, and Ezibuy (Albertson 2009). There are more than 30,000 retail outlets spread throughout New Zealand, including supermarkets, department stores, clothing retailing, footwear retailing, furniture retailing, houseware retailing, toy and game retailing, stationery goods retailing, domestic appliances, and softgoods. New Zealand has more than 150 national and regional chains operating about 7,500 stores. New Zealanders spend more than $\$ 12,000$ in shops every year, for every adult, child, and baby. That adds up to annual retail sales of more than $\$ 65$ billion. The industry employs 325,000 people, about 17 percent of the national workforce.

The traditional relationship between retailers and suppliers is described as a transactional basis, as each party is most concerned with its own interests. However, some retailers and suppliers have made great efforts to develop strategic partnerships since foreign retailers brought in the concept of supply chain collaboration in the last few years. The drive to deploy this kind of system often comes from business pressure to take the cost out of transactions. The suppliers have to improve the documentation and subsequent delivery of goods. Progressive Enterprise, which operates Foodtown, Woolworths, and Countdown chains, for example, works closely with its suppliers to improve its service level to at least 97 percent by involving suppliers in an ongoing co-managed inventory process. Its suppliers send their representatives to work with Progressive to ensure that forecasts and data are accurate, so they can see both sets of data and how they work to create an electronic order, an advance shipping notice to advise Progressive as to what the stores will receive, and a purchase order adjustment (POA) document for the suppliers to agree to order adjustments before shipment. With the variety of relationships between retailers and suppliers, the selected companies offer a good mixture of scenarios for the purpose of this study.

The sample was selected from the New Zealand Business Who's Who, the New Zealand Business Directory, and Kompass. The respondents were selected by checking their company types and product descriptions that suited this research. Duplicate listings were deleted, leaving 400 firms. The targeted key informants who filled out the questionnaires included general managers, marketing managers, logistics managers, and purchasing managers. Respondents were instructed to 
complete the entire questionnaires in reference to their relationship with a specific trading partner.

Several techniques were used to motivate respondents to participate in this research (Dillman 1978). First, the survey was accompanied by a cover letter that described the objectives of the study and the contributions it made to supplier-retailer collaboration. Second, the cover letter also stated that the Massey University Human Ethics Committee (MUHEC) had approved the survey with PN Protocol 02/107, which increased the legitimacy of the survey. Third, all respondents were guaranteed anonymity and offered a summary report of the results in exchange for their participation. Fourth, a pre-addressed stamped envelope was provided to make it easy for the respondents to return the completed questionnaires. Finally, respondents who did not reply in four weeks were mailed a reminder letter and another copy of the questionnaires.

After the second round of sending questionnaires to the non-responding firms, the survey produced 140 responses. 28 respondents chose to decline to participate in the study on the basis of company policy. 21 were returned due to missing addressees. 12 respondents stated that their firms had inappropriate supply chain structures, which were irrelevant to this study. There were three questionnaires with excessive missing data. After eliminating these questionnaires, the valid responses were 76 out of 367 representative sample firms, resulting in a re- sponse rate of 21 percent. This response rate is comparable to the previous study on supply chain management in New Zealand (Basnet et al. 2003), and provides adequate data for further analysis (Malhotra and Grover 1998).

The non-response bias was tested by comparing early and late respondents (Armstrong and Overton 1977). The data set was divided into three according to the number of days from initial mailing until receipt of the returned questionnaires. The basic rationale is that late respondents are more similar to non-respondents than are early respondents. There is no significant difference $(p>.10)$ in the means responses between early and late respondents for all included variables. This finding provides reasonable evidence that non-response bias is not a problem in the data.

Respondents represent mostly some form of retailing (50\%) but also include manufacturers (38.16\%), and distributors (11.84\%). The average annual sales of the respondents is between NZ\$25-50 million. The average number of employees is about 250 people. The respondents have been involved in the supplier-retailer collaboration for an average of two years. The respondents are spread across six broad product categories. Clothing and footwear comprise 22.37 percent, food and beverages 21.05 percent, home improvement and building supplies 19.74 percent, electronics and appliances 18.42 percent, stationery and toys 10.53 percent, and health prod- 


\section{Sridharan \& Simatupang-Managerial Views of Supply Chain Collaboration}

ucts 7.89 percent of the sample. The resulting sample reflects the diversity of the retailer-supplier link inherent in the marketplace. Since the size of the sample is considered small, there is no attempt to classify and contrast the practice of collaboration across different sizes of companies since the intention is to explore the relationship between collaborative practice and operational performance.

\section{Data Analysis}

The collected data provide a basis for measurement validation and statistical analysis. For measurement validation, conventional methods are used, including coefficient alpha, item-tototal correlations, and exploratory factor analysis (Bienstock et al. 1997; Churchill 1979). The threshold value of the criteria for assessing adequate measurement properties is greater than 0.7 , above the minimum level suggested by Nunnally (1978). Factor analysis is used to assess the measurement quality of the conceptual model because it allows a stringent test of the convergent and discriminant validity of the constructs in this study (Guinan et al. 1998). Consistent with the conceptualization, DS, IA, and IS are specified as three factors. Construct validity is supported by the fact that the loading of each item on its respective scale is greater than 0.49 . Low correlation between a factor and its non-associated items indicates a support for discriminant validity. Table 1 lists the scale items, factor loadings, means, standard deviations, and coefficient alphas for the predictors. The results of factor analysis in Table 1 provide statistical evidence of the convergent and discriminant validity of the three dimensions in the study. Two items of information sharing (inventory cost data and sharing collaborative cost) and one item of decision synchronization (creating joint forecast) cross-load on factors with which they are not supposed to be related and have been deleted (Hair et al. 2005). The reasons for this deletion might be related to little attention given for cost reduction efforts between parties and limited efforts given to create joint forecast. The chain members more emphasize sharing forecast data rather than joint forecasting for avoiding difficulties in intensive meetings between parties to identify and resolve exceptions when conducting joint forecasting. The second interpretation is the wide range of collaborative continuum amongst respondents that might be a small portion of them practice full collaboration such as Collaborative Planning, Forecasting, and Replenishment (CPFR) (Basnet et al. 2003). After removing the items not convergent to the predetermined scale, measures of Cronbach's alphas range from 0.71 to 0.82 , which indicate an acceptable reliability of internal consistency.

Cronbach's alphas for performance variables are also estimated. Performance criteria of fulfillment, inventory, and responsiveness have Cronbach's alpha scores of $0.77,0.83$, and 0.71 , respectively. These reliabil- 
Gadjah Mada International Journal of Business, May-August 2009, Vol. 11, No. 2

Table 1. Measurement Statistics for Predictor Variables

\begin{tabular}{|c|c|c|c|c|c|c|}
\hline \multirow[b]{2}{*}{ Scales of Collaborative Practice } & \multicolumn{3}{|c|}{ Rotated Component Matrix } & \multirow[b]{2}{*}{ Mean } & \multicolumn{2}{|c|}{ Std. Cronbach's } \\
\hline & Factor 1 & Factor 2 & Factor 3 & & Dev. & $\begin{array}{l}\text { ronbacn's } \\
\text { Alpha }\end{array}$ \\
\hline \multicolumn{7}{|l|}{ Decision Synchronization (DS) } \\
\hline DS1: Reducing demand fluctuations & .757 & .014 & .197 & & & \\
\hline DS3: Co-managing stock/inventory & .638 & .520 & .205 & & & \\
\hline DS4: Ensuring on-time delivery & .742 & .278 & .186 & 2.13 & .86 & .816 \\
\hline DS5: Improving product availability & .729 & .101 & .234 & & & \\
\hline IS3: Inventory cost data (deleted) & .678 & .678 & .341 & & & \\
\hline IA3: Sharing collaborative cost (deleted) & .670 & .419 & .149 & & & \\
\hline \multicolumn{7}{|l|}{ Information Sharing (IS) } \\
\hline IS1: Data about promotional events & .463 & .499 & -.170 & & & \\
\hline IS2: Data about sales forecast & .220 & .590 & .361 & 3.23 & .89 & .768 \\
\hline IS4: On-hand inventory levels data & .103 & .846 & .108 & & & \\
\hline IS5: Order tracking data & .347 & .767 & .033 & & & \\
\hline DS2: Creating joint forecasts (deleted) & .458 & .492 & .459 & & & \\
\hline \multicolumn{7}{|l|}{ Incentive Alignment (IA) } \\
\hline IA1: Sharing risks of uncertainty & .299 & -.247 & .600 & & & \\
\hline IA2: Sharing saving from lowered stock & .298 & .067 & .688 & 3.36 & .77 & .711 \\
\hline IA4: Focusing on generating sales & .067 & .163 & .781 & & & \\
\hline IA5: Sharing benefits of collaboration & .037 & .434 & .709 & & & \\
\hline
\end{tabular}

ity coefficients show a high degree of internal consistency amongst these variables.

For each variable, scale scores are computed as the average of the individual items. The profiles of the scores for predicted variables then serve as inputs for regression analysis. Several tests for the assumptions of linearity, independence, and normality are carried out to ensure that the data could be used to apply a valid regression model. First, scatter plots of the individual independent variables do not indicate nonlinear relationships between Information Sharing (IS), Decision Syn- chronization (DS), and Incentive Alignment (IA). Second, tests for heteroscedascity do not find any variable violating the assumption of constant variance. Finally, the tests of normality using the Kolmogorov DStatistics, skewness, and kurtosis do not find any variable violating the assumption of normality. The predicator variables are found to be not correlated amongst themselves (IS and DS is .58, IS and IA is .32, and DS and IA is .47). The regression analysis is used in this research to test the effect of the three factors of collaborative practice on performance. This procedure deter- 
mines whether there is a significant effect of the independent variables as specified in the hypotheses (Cohen and Cohen 1983).

\section{Discussion}

The main purpose of this study is to provide a new insight into the conceptual link between the interface factors of collaborative practice and operational performance. The hypotheses are tested through data analysis. Major findings are discussed as follows.

All hypotheses stated in the modelling section are tested by estimating the regression equation for each performance criterion. The estimation results for the first three hypotheses are summarized in Table 2. The Ftests for the three regression equations indicate the linear relationship between predictor variables and realized performance with alphas less than 0.001 . The regression equations vary in values of adjusted coefficients of determination. The first regression equation accounts for about 60 percent of the variation in fulfillment performance. The second regression equation accounts for about 54 percent of the variation in inventory performance. The third regression equation accounts for about 33 percent of the variation in responsiveness performance. The results substantiate the three hypotheses. All being equal, realized performance is greater when information sharing, decision synchronization, and incentive alignment are higher.

Testing Hypothesis 1: Hypothesis 1 relates to the relationship between information sharing and operational performance. As expected, information sharing significantly helps the chain members achieve better fulfillment $(\beta=0.225)$, lowered inventory ( $\beta=0.489$ ), and higher responsiveness $(\beta=0.199)$. This finding is consistent with previous research on the impact of information sharing on the performance of supply chain (Fawcett et al. 2009; Fisher 1997). Through information sharing, the chain members are able to take into account factors affecting the future requirements of fulfillment, inventory, and

Table 2. Standardized Beta Coefficients for Realized Operational Performance

\begin{tabular}{|c|c|c|c|}
\hline \multirow[b]{2}{*}{ Hypotheses } & \multicolumn{3}{|c|}{ Performance Criteria } \\
\hline & Fulfillment & Inventory & Responsiveness \\
\hline H1. Information Sharing (IS) & $.225 * *$ & $.489 * * *$ & $.199 *$ \\
\hline H2. Decision Synchronization (DS) & $.496 * * *$ & $.380 * * *$ & $.423 * * *$ \\
\hline H3. Incentive Alignment (IA) & $.226 * * *$ & -.077 & .066 \\
\hline Adjusted $R$ square & .602 & .537 & .329 \\
\hline
\end{tabular}

Note: $* p<.10$, one-tailed test; ${ }^{* *} p<.05$, one-tailed test, $* * * p<.01$, one-tailed test, - Not statistically significant. 
responsiveness. Shared information can be used to better coordinate order and replenishments in reducing inventory costs and improving customer service levels.

Testing Hypothesis 2: Hypothesis 2 states that decision synchronization influences better performance. It is found that decision synchronization significantly contributes to fulfillment ( $b=0.496)$, inventory $(b=0.380)$, and responsiveness performance $(b=$ $0.423)$. This finding is consistent with previous research on the effect of collaborative decision making on supply chain performance (Holweg etal. 2005; Stank et al. 2001). The chain members are able to attain better view of planning, monitoring, and coordination of the overall supply chain processes (Morash and Clinton 1998). They can synchronize their decisions on product planning, ordering, and replenishment that enable them to fulfil current and future demand with minimum inventory. Collaborative decision making also helps them carry out improvements such as shortening cycle time that affects their ability to respond more quickly to demand changes (Simchi-Levi et al. 2007).

Testing Hypothesis 3: Hypothesis 3 states that incentive alignment has a positive relationship to operational performance. It is found that incentive alignment contributes only to fulfillment performance $(\beta=0.226)$. There is no significant impact of incentive alignment on lowered inventory and higher responsiveness. This finding indicates that the chain mem- bers consider fulfillment to be the basic criterion to satisfy customer needs and a means of incentive alignment (Giunipero et al. 2001). This is because fulfillment performance specifies clearly an agreement between two parties where the supplier delivers orders by a predetermined due date including the payment arrangement. For instance, a large retailer in New Zealand often requires their suppliers to send orders within pre-specified delivery time windows. The suppliers will be charged for sending orders earlier or tardier than this time window. Furthermore, as both parties enjoy inventory and responsiveness from collaboration, the benefits of inventory and responsiveness serve as selfimposed incentives. In other words, incentive alignment is often embedded in this collaborative effort. This means both parties would reap the benefits of lowered inventory and fast responsiveness if they are to cooperate closely in information sharing and decision synchronization without devising incentive alignment (Fisher 1997; Stank et al. 1999).

The three factors of collaborative practice provide opportunities to improve supply chain performance. The findings suggest that information sharing, decision synchronization, and incentive alignment are important determinants of operational performance. It has been found that information sharing and decision synchronization consistently contribute to fulfillment, inventory, and responsiveness performance. However, incentive alignment 


\section{Sridharan \& Simatupang-Managerial Views of Supply Chain Collaboration}

is found to only affect fulfillment performance. This is not unusual for the chain members that prioritize fulfillment as a key performance indicator of customer service level (Croxton 2003). It appears that the chain members should put together information sharing, decision synchronization and incentive alignment if they want to improve their fulfillment performance. Furthermore, information sharing and decision synchronization are both important to attaining better inventory and responsiveness. This finding also suggests that the chain members should identify alternative incentive schemes if they prioritize inventory reduction and better responsiveness as key performance indicators of the relationships (Corbett et al. 1999; Narayanan and Raman 2004).

Further research should firstly concentrate on developing alternative measures of operational performance. This study employs operational measures of performance. An important area for future research is to include financial measures of performance because it would be useful for the participating members to confirm the relationship between collaborative practice and financial performance (Corbett et al. 1999; Wisner 2003). Next, this research can be extended to examine the antecedents of collaborative practice such as interdependence, top management support, trust, commitment, power disparity, and organizational capability (Mentzer et al. 2000; Mohr and Spekman 1994; Sheu et al. 2006). Third, the focus of this research is on the retailer-supplier link. The conceptual model can be modified to examine other links along the supply chain such as the manufacturer-distributor, the manufacturer-logistics, and the retailer-logistic service providers. Finally, there is also an opportunity to study the complicated interaction of antecedents, collaborative practice, and performance using structural equation model with a larger sample size (Wisner 2003).

\section{Conclusions}

Research questions addressed in this study is the strength of relationship between collaborative practice and operational performance. A conceptual model and an empirical study are undertaken to answer this research question.

The study seeks to make a contribution to the theory and practice of supply chain collaboration. The first contribution is the demonstration that supply chain collaboration can be measured using three factors: (1) decision synchronization, (2) information sharing, and (3) incentive alignment. Information sharing enables the chain members to realize that it is important to take into account a global perspective in making optimal decisions. Decision synchronization enables the chain members to agree upon joint decisions, such as collaborative forecasting, ordering, and delivery. Incentive alignment encourages the chain members to pursue mutual strategic objectives that yield better profits to 
Gadjah Mada International Journal of Business, May-August 2009, Vol. 11, No. 2

all members through sharing costs, benefits, and risks. The study's second contribution lies in its demonstration of the empirical examination of the impact of collaborative practice on operational performance.

The study statistically describes some important findings on collaborative practice. Results show that information sharing, decision synchronization, and incentive alignment significantly contribute to fulfillment performance. Information sharing and decision synchronization consistently affect fulfillment, inventory, and responsiveness performance.
Although this research confirms that collaborative practice provides benefits to participating members in terms of improved operational performance, there are a number of opportunities for further research. Several important ideas are to include financial performance as a key success measure of collaboration and to use structural equation model to capture more interaction between key factors of collaborative practice and performance. Moreover, it would be useful to explore antecedent variables of collaborative practice and expand the study across other industries.

\section{References}

Albertson, J. 2009. The Retail Market in New Zealand: An Analysis - 2009. Auckland: NZ Retailers Association.

Armstrong, J. S., and T. S. Overton. 1977. Estimating non-response bias in mail surveys. Journal of Marketing Research 14 (3): 396-402.

Ballou, R. H., S. M. Gilbert and A. Mukherjee. 2000. New managerial challenges from supply chain opportunities. Industrial Marketing Management 29 (1): 7-18.

Barratt, M., and A. Oliveira. 2001. Exploring the experiences of collaborative planning initiatives. International Journal of Physical Distribution and Logistics Management 31 (4): 266-89.

Basnet, C., J. Corner, J. Wisner and K.-C. Tan. 2003. Benchmarking supply chain management practice in New Zealand. Supply Chain Management: An International Journal 8 (1): 57-64.

Bienstock, C. C., J. T. Mentzer and M. M. Bird. 1997. Measuring physical distribution service quality. Journal of the Academy of Marketing Science 25 (1): 31-44.

Churchill, G.A. 1979. A paradigm for developing better measures of marketing constructs. Journal of Marketing Research 16 (1): 64-73.

Bowersox, D.J. 1990. The strategic benefits of logistics alliances. Harvard Business Review 68 (4): 36-43.

Bowersox, D. J., D. J. Closs, and T. P. Stank. 2000. Ten mega-trends that will revolutionize supply chain logistics. Journal of Business Logistics 21 (2): 1-16.

Bowersox, D. J., D. J. Closs, and T. P. Stank. 2003. How to master cross-enterprise collaboration. Supply chain Management Review 7 (4): 18-27. 
Sridharan \& Simatupang-Managerial Views of Supply Chain Collaboration

Buzzell, R. D., and G. Ortmeyer. 1995. Channel partnerships streamline distribution. Sloan Management Review 36 (3): 85-96.

Cavana, R. Y., B. L. Delayahe, and U. Sekaran. 2001. Applied Business Research: Qualitative and Quantitative Methods. Milton, Qld: Wiley.

Cohen, J., and P. Cohen. 1983. Applied Multiple Regression/Correlation Analysis for the Behavioral Sciences ( ${ }^{\text {nd }}$ ed.). Hillsdale, NJ: Erlbaum Associates.

Corbett, C. J., J. D. Blackburn, and L. N. van Wassenhove. 1999. Partnerships to improve supply chains. Sloan Management Review 40 (4): 71-82.

Croxton, K. L. 2003. The order fulfillment process. The International Journal of Logistics Management 14 (1): 19-32.

Dillman, D. 1978. Mail and Telephone Surveys. New York, NY: Wiley.

Dyer, J. H., and H. Singh. 1998. The relational view: cooperative strategy and sources of interorganizational competitive advantage. Academy of Management Review 23 (4): 660-679.

Fawcett, S. E., C. Wallin, C. Allred, and G. Magnan. 2009. Supply chain informationsharing: benchmarking a proven path. Benchmarking: An International Journal 16 (2): 222-246.

Fisher, M. L. 1997. What is the right supply chain for your product? Harvard Business Review 75 (2): 105-116.

Frankel, R., T. J. Goldsby, and J. M. Whipple. 2002. Grocery industry collaboration in the wake of ECR. The International Journal of Logistics Management 13 (1): 57-72.

Giunipero, L. C., S. S. Fiorito, D. H. Pearcy, and L. Dandeo. 2001. The impact of vendor incentives on quick response. The International Review of Retail, Distribution and Consumer Research 11 (4): 359-76.

Guinan, P. J., J. G. Cooprider, and S. Faraj. 1998. Enabling software development team performance during requirements definition: A behavioural versus technical approach. Information Systems Research 9 (2): 101-125.

Hair, J.F., B. Black, B. Babin, R. E. Anderson, and R. L. Tatham. 2005. Multivariate Data Analysis (6 ${ }^{\text {th }}$ ed.). Upper Saddle River, NJ: Prentice Hall.

Holweg, M., S. Disney, J. Holmström, J. Småros. 2005. Supply chain collaboration: making sense of the strategy continuum. European Management Journal 23 (2): 170-181.

Ireland, R., and R. Bruce. 2000. CPFR only the beginning of collaboration. Supply Chain Management Review 4 (4): 80-8.

Johnston, R., and P. R. Lawrence. 1988. Beyond vertical integration - the rise of the valueadding partnership. Harvard Business Review 66 (4): 94-101.

Lambert, D. M., M. A. Emmelhainz, and J. T. Gardner. 1999. Building successful partnerships. Journal of Business Logistics 21 (1): 165-181.

Lee, H. L. 2000. Creating value through supply chain integration. Supply Chain Management Review 4 (4): 30-36. 
Gadjah Mada International Journal of Business, May-August 2009, Vol. 11, No. 2

Lee, H. L., V. Padmanabhan, and S. Whang. 1997. The bullwhip effect in supply chains. Sloan Management Review 38 (3): 93-102.

Lee, H. L., and S. Whang. 1999. Decentralized multi-echelon supply chains: Incentives and information. Management Science 45 (5): 633-640.

Malhotra, M. J., and V. Grover. 1998. An assessment of survey research in POM: From construct to theory. Journal of Operations Management 16 (4): 407-425.

Mentzer, J. M., S. Min and Z. G. Zacharia. 2000. The nature of interfirm partnering in supply chain management. Journal of Retailing 76 (4): 549-568.

Mohr, J., and R. Spekman. 1994. Characteristics of partnership success: partnership attributes, communication behaviour, and conflict resolution techniques. Strategic Management Journal 15 (2) 135-152.

Morash, E. A., and S. R. Clinton. 1998 Supply chain integration: Customer value through collaborative closeness versus operational excellence. Journal of Marketing Theory and Practice 6 (4): 104-120.

Narayanan, V. G., and A. Raman. 2004. Aligning incentives in supply chains. Harvard Business Review 82 (11): 94-102.

Narus, J. A., and J. C. Anderson. 1996. Rethinking distribution: adaptive channels. Harvard Business Review 74 (4): 112-120.

Nunnally, J. C. 1978. Psychometric Theory. New York, NY: McGraw-Hill.

Parks, L. 1999. CRP investment pays off in many ways. Drug Store News 21 (2): 26.

Pinsonneault, A., and K. L. Kraemer. 1993. Survey research methodology in management information systems: An assessment. Journal of Management Information System 10 (2): 75-105.

Ramdas, K., and R. E. Spekman. 2000. Chain or shackles: understanding what drives supply-chain performance. Interfaces 30 (4): 3-21.

Sankaran, J. K. 2000. Freight logistics in the New Zealand context. International Journal of Physical Distribution and Logistics Management 30 (2): 145-164.

Sherman, R. J. 1998. Collaborative planning, forecasting and replenishment (CPFR). Journal of Marketing Theory and Practice 6 (4): 6-9.

Sheu, C., H. R. Yen, and B. Chae. 2006. Determinants of supplier-retailer collaboration: Evidence from an international study. International Journal of Operations and Production Management 26 (1): 24-49.

Simchi-Levi, D, P. Kaminsky, and E. Simchi-Levi. 2007. Designing and Managing the Supply Chain ( $3^{\text {rd }}$ ed.). New York: McGraw-Hill Irwin.

Simatupang, T. M., and R. Sridharan. 2002. The collaborative supply chain. The International Journal of Logistics Management 13 (1): 15-30.

Simatupang, T. M., and R. Sridharan. 2005. Supply chain discontent. Business Process Management Journal 11 (4): 349-369.

Spekman, R. E., J. W. Kamauff, and N. Myhr. 1998. An empirical investigation into supply chain management: A perspective on partnership. Supply Chain Management: An International Journal 3 (2): 53-67. 
Sridharan \& Simatupang-Managerial Views of Supply Chain Collaboration

Stank, T. P., M. R. Crum, and M. Arango. 1999. Benefits of interfirm coordination in food industry supply chains. Journal of Business Logistics 20 (2): 21-42.

Stank, T. P., S. B. Keller, and P. J. Daugherty. 2001. Supply chain collaboration and logistical service performance. Journal of Business Logistics 22 (1): 29-47.

Whipple, J. M., R. Frankel, and P. J. Daugherty. 2002. Information support for alliances: performance implications. Journal of Business Logistics 23 (2): 67-81.

Whipple, J. M., and D. Russell. 2007. Building supply chain collaboration: A typology of collaborative approaches. The International Journal of Logistics Management 18 (2): 174-196.

Wisner, J. 2003. A structural equation model of supply chain strategies and firm performance. Journal of Business Logistics 24 (1): 1-26.

Zhao, M., C. Dröge and T. P. Stank. 2001. The effects of logistics capabilities on firm performance: customer-focused versus information-focused capabilities. Journal of Business Logistics 22 (2): 91-107. 